Anxiety and musculoskeletal pain: role of astrocytes - supplementary information

\title{
The impact of anxiety on chronic musculoskeletal pain and the role of astrocyte activation
}

\section{Supplementary Information}

\section{Additional Abbreviations}

ICC: Intra-class correlation, IHC: Immunohistochemistry.

\section{Supplementary Results}

\section{Anxiety-like behaviour in rats \\ Open Field test (SD versus WKY)}

Compared to SD rats, WKY rats showed reduced entries into the central zone $(3.4 \pm 0.9$ versus $5.2 \pm 0.9, p=0.026)$ with a lower total duration $(15 \pm 2 \%$ versus $35 \pm 4 \%$, $\mathrm{p}=0.0001)$. WKY rats also displayed reduced activity, with significantly lower total exploratory distance $(1.6 \pm 0.1 \mathrm{~m}$ versus $3.0 \pm 0.1 \mathrm{~m}, \mathrm{p}<0.0001$, Figure S1).

\section{Elevated Plus Maze (Wistar versus WKY)}

For an in-depth analysis of anxiety-like behaviour, the more robust elevated plus maze paradigm was utilised. Wistar rats were used as the control strain in these experiments to reduce any influence of differing genetic background on our observations. At baseline, no significant strain difference in duration in open zones was observed (Wistar $A \cup C=38.5 \pm 14.7$, versus $W K Y A U C=26.7 \pm 11.8$, data not shown), although a trend towards reduced duration was noted in WKY rats, and they did display a significant increased latency to enter the open outer arm (WKY $=561.9 \pm 27.8 \mathrm{~s}$ versus Wistar $=370.4 \pm 55.1 \mathrm{~s}, \mathrm{p}=0.009$, data not shown) suggesting an anxiety-like phenotype. At D21, a significant strain difference in open arm duration was observed, with WKY rats spending less time that Wistar rats in the open zones (WKY AUC $=3.5 \pm 4.1$, versus Wistar $A \cup C=19.9 \pm 3.5, p<0.01$, data not shown). Interestingly, when rats were stratified by treatment (MIA versus saline) and strain, no effect of OA status on anxietylike behaviour was noted. These data suggest that WKY rats have a predisposition towards anxiety which is expressed by the stresses associated with repeated handling and behavioural testing.

To identify potential parallels between our clinical and preclinical data, odds ratios for the association between anxiety, OA status, and $O A$ and referred pain were calculated as described in the methods. Table S3 demonstrates that anxiety at baseline was not predictive of OA pathology $(\mathrm{p}=0.85)$, nor ipsilateral pain $(\mathrm{p}=0.46)$, but was associated with an increase in anxiety (i.e. basal anxiety is partially predictive of anxiety induced by the model, $p=0.063)$ and strongly associated with contralateral pain $(p=0.0014)$, suggesting that anxiety drives the widespread pain phenotype seen in both our knee pain patients (Table 2) and the preclinical model (Table 3).

\section{Glial cell involvement in enhanced OA pain in anxious WKY rats}

MIA administration resulted in activation of astrocytes in pain- associated regions of the CNS in high-anxiety WKY rats (Figures $3 \& 4$ ), as evidenced by the elevated GFAP expression seen in spinal cord, PAG, and ACC. In contrast, normo-anxiety SD rats showed elevated GFAP in ipsilateral spinal cord only, with no changes observed in the PAG or ACC (Figure S3). These data indicate an association between elevated anxiety, supraspinal astrogliosis, and contralateral pain in the MIA model. 
Anxiety and musculoskeletal pain: role of astrocytes - supplementary information

An increase in microglial activation was observed in the ipsilateral spinal cord of both strains (Figure S4), with no significant difference between strains, suggesting that elevated anxiety does not lead to increased microglial activation in the spinal cord. 
Anxiety and musculoskeletal pain: role of astrocytes - supplementary information

\section{Supplementary Figures}
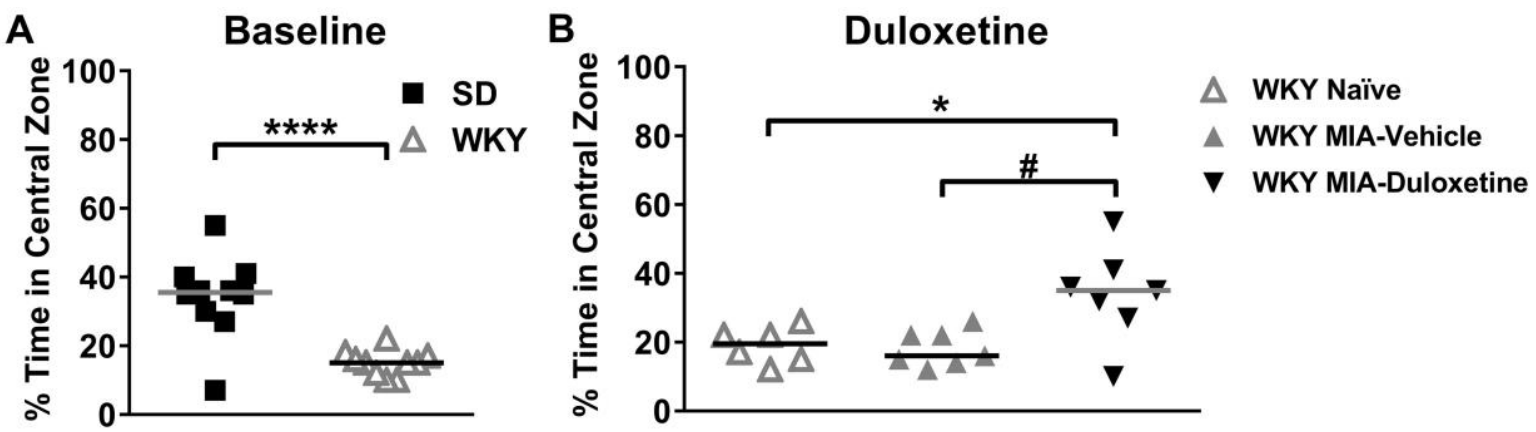

Supplementary Figure S1: WKY rats display an anxious phenotype in the open field test

(A) WKY rats spend less time in the central zone of the open field than their SD counterparts $(15 \pm 1.1 \mathrm{~s}$ versus $34.2 \pm 3.8 \mathrm{~s}, \mathrm{p}<0.0001)$. This phenotype is still present after MIA administration, and is reversed after 3 daily injections of duloxetine (B). 
Anxiety and musculoskeletal pain: role of astrocytes - supplementary information

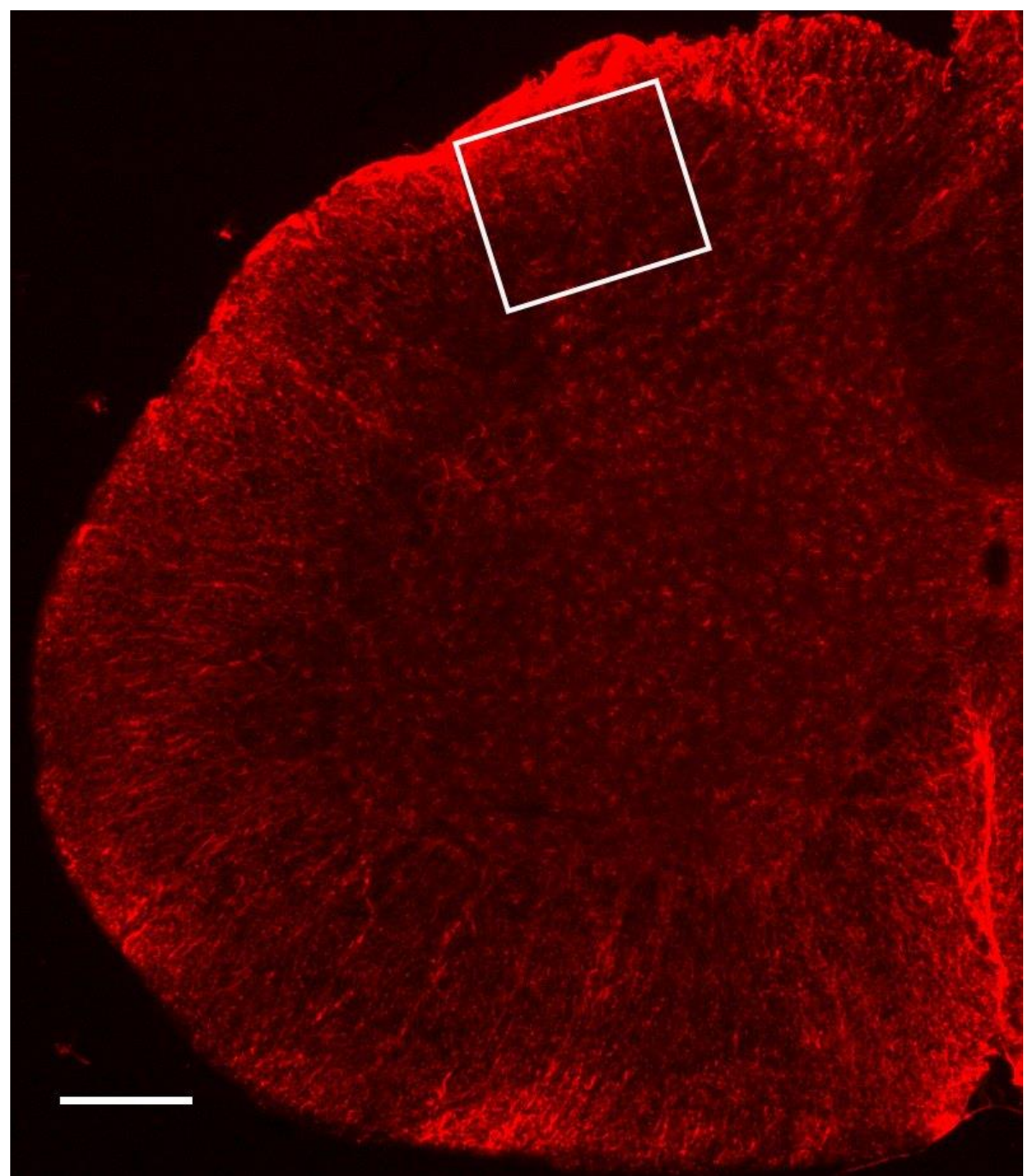

Supplementary Figure 2: Low magnification image depicting spinal GFAP labelling in an MIA-treated WKY rat

Low magnification $(5 x)$ image GFAP labelling in the ipsilateral side of a lumbar spinal cord section from a WKY rat treated with MIA. The white boxed region depicts the ROI used for higher magnification imaging and quantification of GFAP expression.

Scale bar $=250 \mu \mathrm{m}$ 


\section{ROIs for GFAP Analysis}

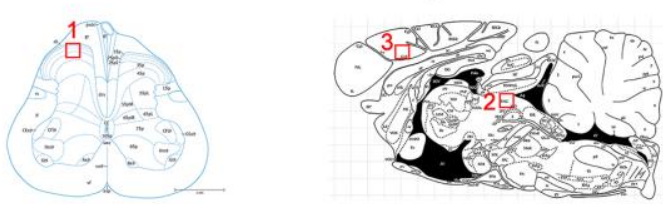

\section{PAG GFAP Expression}
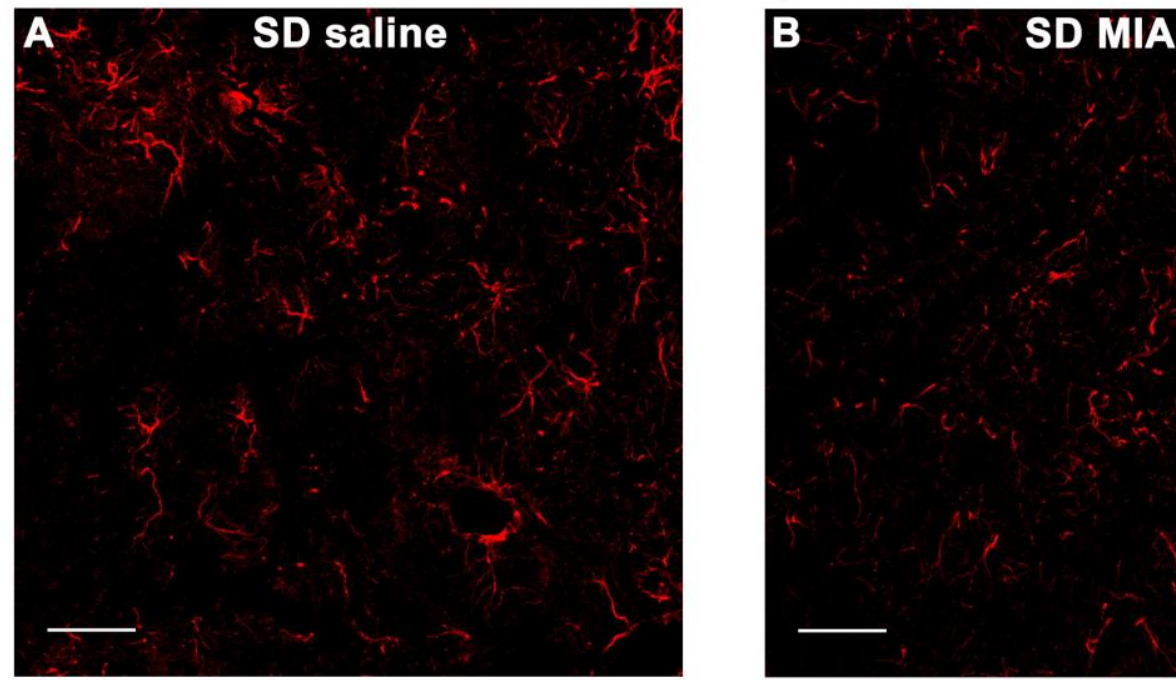

\section{ACC GFAP Expression}

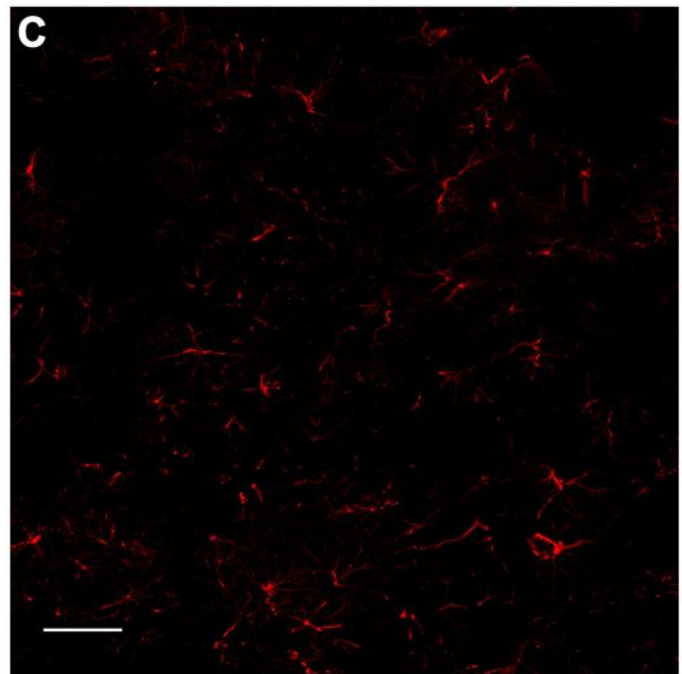

D

Supplementary Figure S3: Intra-articular injection of MIA in SD rats does not induce astrocyte activation in the ACC or PAG. Schematics depicting the ROIs imaged in the spinal cord dorsal horn (1), PAG (2) and ACC (3). Representative images of showing no difference in GFAP immunofluorescence in the PAG and ACC between SD-saline (A \& C) and SD-MIA rats. Scale bar $=50 \mu \mathrm{m}$ 


\section{Spinal Microglial Activation in the MIA Model}
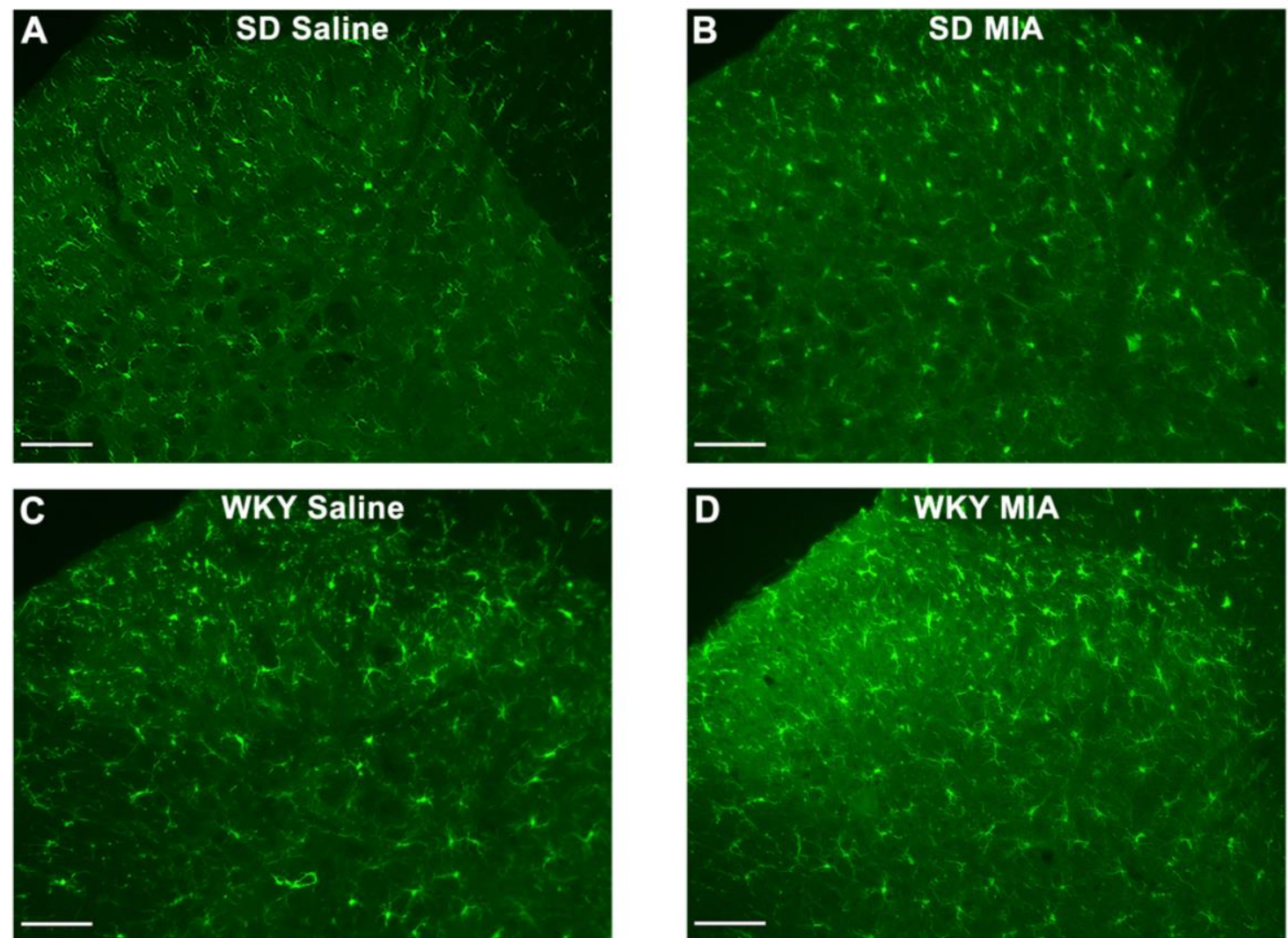

Supplementary Figure S4: Lack of strain differences in MIA-induced changes in spinal cord IBA-1 and phospho-p38 (P-p38) immunofluorescence.

Representative images of microglial cells, marked by ionized calcium binding adapter molecule (IBA-1) immunofluorescence, in the ipsilateral spinal cord of SD rats treated with saline $(\mathbf{A})$ or MIA $(\mathbf{B})$, and WKY rats treated with saline $(\mathbf{C})$ or MIA (D).

Scale bars $=50 \mu \mathrm{m}$ 
Anxiety and musculoskeletal pain: role of astrocytes - supplementary information

Table S1: Association between pain thresholds, pain scores, and anxiety and depression scores

\begin{tabular}{|c|c|c|c|c|c|c|}
\hline \multirow[b]{2}{*}{ Comparison } & \multicolumn{3}{|c|}{ Anxiety Score } & \multicolumn{3}{|c|}{ Depression Score } \\
\hline & beta & $95 \% \mathrm{Cl}$ & p-value & beta & $95 \% \mathrm{Cl}$ & p-value \\
\hline $\begin{array}{l}\text { Constant } \\
\text { Pain } \\
\text { Intensity }\end{array}$ & 0.095 & $\begin{array}{l}(0.060 \\
0.129)\end{array}$ & $\underset{\star \star \star x \star \star}{0.0000001}$ & 0.093 & $\begin{array}{l}(0.046 \\
0.140)\end{array}$ & $\underset{* \star \star}{0.00011}$ \\
\hline $\begin{array}{c}\text { Intermittent } \\
\text { Pain } \\
\text { Intensity }\end{array}$ & 0.062 & $\begin{array}{c}(0.028 \\
0.095)\end{array}$ & $\underset{* \star \star \star *}{0.0004}$ & 0.064 & $\begin{array}{c}(0.019 \\
0.108)\end{array}$ & $\underset{\star \star}{0.0053}$ \\
\hline $\begin{array}{l}\text { Visual } \\
\text { Analogue } \\
\text { Scale }\end{array}$ & 0.142 & $\begin{array}{c}(0.073 \\
0.211)\end{array}$ & 0.00005 & 0.229 & $\begin{array}{c}(0.141 \\
0.318)\end{array}$ & $\underset{\star \star \star \star \star \star \star}{0.0000004}$ \\
\hline $\begin{array}{c}\text { Anterior } \\
\text { Tibia PPT }\end{array}$ & -0.009 & $\begin{array}{l}(-0.016 \\
-0.001)\end{array}$ & $\underset{*}{0.0222}$ & -0.011 & $\begin{array}{l}(-0.021 \\
-0.002)\end{array}$ & $\underset{*}{0.0228}$ \\
\hline $\begin{array}{c}\text { Knee } \\
\text { Lateral PPT }\end{array}$ & -0.011 & $\begin{array}{l}(-0.018 \\
-0.003)\end{array}$ & $\underset{* \star}{0.008}$ & -0.015 & $\begin{array}{l}(-0.025 \\
-0.004)\end{array}$ & $\underset{\star \star}{0.0053}$ \\
\hline $\begin{array}{c}\text { Knee } \\
\text { Medial PPT }\end{array}$ & -0.001 & $\begin{array}{l}-0.017 \\
-0.002)\end{array}$ & $\begin{array}{c}0.0144 \\
*\end{array}$ & -0.013 & $\begin{array}{l}(-0.022 \\
-0.003)\end{array}$ & $\underset{*}{0.0142}$ \\
\hline $\begin{array}{l}\text { Sternum } \\
\text { PPT }\end{array}$ & -0.022 & $\begin{array}{l}(-0.041 \\
-0.003)\end{array}$ & $\underset{*}{0.0243}$ & -0.023 & $\begin{array}{c}(-0.049 \\
0.002)\end{array}$ & $\begin{array}{c}0.0708 \\
\text { NS }\end{array}$ \\
\hline
\end{tabular}

Linear regression analyses carried out in the whole sample $(n=230)$ adjusting for age, gender, BMI and OA status, without stratifying for knee pain. All variables considered were found to be significantly correlated with anxiety and depression HADS scores after adjustment for potential confounders. 
Anxiety and musculoskeletal pain: role of astrocytes - supplementary information

Table S2: Lack of strain differences in baseline nociceptive thresholds.

\begin{tabular}{|c|ccc|}
\cline { 2 - 4 } \multicolumn{1}{c|}{} & SD (baseline) & WKY (baseline) & P value \\
\hline $\begin{array}{c}\text { Weight-bearing } \\
\text { asymmetry (g) }\end{array}$ & $0.3 \pm 1.9$ & $-0.8 \pm 1.1$ & $>0.05$ \\
\hline $\begin{array}{c}\text { Ipsilateral PWT } \\
\text { (g) }\end{array}$ & $20 \pm 2.1$ & $18.4 \pm 2.2$ & $>0.05$ \\
\hline $\begin{array}{c}\text { Contralateral } \\
\text { PWT (g) }\end{array}$ & $22.7 \pm 1.7$ & $17.8 \pm 1.9$ & $>0.05$ \\
\hline
\end{tabular}

Baseline weight-bearing measurements and paw withdrawal thresholds of SD and WKY rats do not significantly differ $(p>0.05$, Mann Whitney $U$ test) 